\title{
The effectiveness of large group demonstration training method on the use of pressurized metered-dose inhaler in elderly with chronic obstructive pulmonary disease
}

\author{
Woranoot Choomuang, Chaicharn Pothirat, Warawut Chaiwong, Chalerm Liwsrisakun, \\ Theerakorn Theerakittikul, Nittaya Phetsuk, Panida Chanayat
}

Division of Pulmonary, Critical Care, and Allergy, Department of Internal Medicine, Faculty of Medicine, Chiang Mai University, Chiang Mai, Thailand

Contributions: (I) Conception and design: W Choomuang, C Pothirat, W Chaiwong; (II) Administrative support: C Pothirat, C Liwsrisakun, T Theerakittikul; (III) Provision of study materials or patients: W Choomuang, C Pothirat, W Chaiwong, N Phetsuk, P Chanayat; (IV) Collection and assembly of data: W Choomuang, C Pothirat, W Chaiwong, T Theerakittikul, N Phetsuk, P Chanayat; (V) Data analysis and interpretation: W Choomuang, C Pothirat, W Chaiwong; (VI) Manuscript writing: All authors; (VII) Final approval of manuscript: All authors.

Correspondence to: Chaicharn Pothirat, MD, FCCP. Division of Pulmonary, Critical Care and Allergy, Department of Internal Medicine, Faculty of Medicine, Chiang Mai University, 110 Inthavaroros Rd., Sriphum, Maung Chiang Mai, Chiang Mai 50200, Thailand. Email: chaicharn.p@cmu.ac.th.

Background: Pressurized metered-dose inhaler (pMDI) is the most commonly used inhaler devices in community hospitals in Thailand. However, the research work on large group demonstration training method in the use of pMDI and pMDI with spacer in cases of chronic obstructive pulmonary disease (COPD) is very limited. Therefore, this study aimed to evaluate the effectiveness of this training method in elderly with COPD patients.

Methods: This prospective cross-sectional study was conducted at COPD clinic, Chiang Dao Hospital, Chiang Mai, Thailand between June 2019 and July 2019. All patients being treated in the clinic were assessed for their inhalation technique and inspiratory flow. After the initial assessment, patients were given instructions regarding the correct inhalation technique of pMDI and pMDI with spacer devices through large group demonstration. One month later, inhalation techniques and inspiratory flow were re-assessed.

Results: A total of 104 COPD patients were included, mean age $70.9 \pm 8.3$ years, 51 (49.0\%) male. At their first visit, $75.0 \%$ of pMDI and $81.7 \%$ of pMDI with spacer users performed at least one essential step incorrectly. After receiving large group demonstration training, there was a statistically significant increase in all devices; $26.7 \%$ vs. $56.7 \%$, $\mathrm{P}=0.001$ for correct technique, $41.7 \%$ vs. $62.7 \%, \mathrm{P}=0.026$ for appropriate flow, and $11.7 \%$ vs. $36.7 \%, \mathrm{P}=0.001$ for correct technique and flow.

Conclusions: The provision of large group training significantly increases the correct use of inhalation techniques and inspiratory flow for pMDI and pMDI with spacer in elderly with COPD.

Keywords: Chronic obstructive pulmonary disease (COPD); inhalation; technique; device; flow; metered-dose inhaler (MDI)

Submitted Oct 08, 2021. Accepted for publication Feb 10, 2022.

doi: $10.21037 /$ jtd-21-1612

View this article at: https://dx.doi.org/10.21037/jtd-21-1612

\section{Introduction}

Pharmacological therapy is a mainstay in the management of chronic obstructive pulmonary disease (COPD) (1). Now, many types of devices, including; pressurized metered- dose inhalers (pMDIs), slow-mist inhalers (SMIs), dry powder inhalers (DPIs), and nebulizers are available. pMDI and $\mathrm{pMDI}$ with spacer devices are often used for drug administration for patients with COPD (2). However, the 
pMDI device was the commonly used in community hospital in Thailand. When using pMDI and pMDI with spacer devices, patients need to inhale correctly and coordinate their breathing and actuation to ensure effective drug delivery $(1,3,4)$. Previous studies have shown that a high number of technical technique errors were observed in COPD subjects when using the pMDI (63.5-95.7\%) (5-9), and the pMDI with spacer $(69.7-79.2 \%)$ in the inhalation technique as well as the inspiratory flow $(5,7,8)$. Al-Showair $e t$ al. showed a high percentage $(93.5 \%)$ of COPD subjects use a flow greater than $60 \mathrm{~L} / \mathrm{min}$ with the $\mathrm{pMDI}$ (10). Poor inhalation techniques are associated with decreased medication delivery, poor disease control, and poor quality of life (11-14). Therefore, it is necessary on the part of the physicians, nurses, pharmacist, and other health care providers to understand the issues related to the performance and correct use of inhaler devices. Many methods including face to face training, multimedia counseling, and small group training showed improvement in the correct inhalation technique used in inhaler devices $(5,10,11,15-17)$. However, in a busy clinic, with many crowed patients and limited of time, the group demonstration training method may be more appropriate. Previous findings relating to the use of group training on inhalation techniques showed an improvement of $35 \%$ in the correct use of pMDI (17). However, this study only consisted of small group $(n=5-7)$. Therefore, there is lack of data on large group demonstration training on pMDI and pMDI with spacer in COPD patients. Thus, the objective of this study was to evaluate the effect of the large group demonstration training on inhaler devices in elderly with COPD patients using pMDI and pMDI with spacer. We hypothesized that the large group inhalation training significantly increases the correct use of inhalation techniques and inspiratory flow for pMDI and pMDI with spacer in elderly with COPD. We present the following article in accordance with the STROBE reporting checklist (available at https://jtd.amegroups.com/article/ view/10.21037/jtd-21-1612/rc).

\section{Methods}

\section{Study design}

This prospective cross-sectional study was conducted at the COPD clinic, outpatient department of Chiang Dao Hospital, Chiang Dao District in Chiang Mai, Thailand between June 2019 and July 2019. The COPD patients were assessed using the devices available in Chiang Dao
Hospital including $\mathrm{pMDI}$ and $\mathrm{pMDI}$ with spacer.

\section{Study population}

Stable COPD patients with age greater than 60 years old, previously diagnosed in accordance with the Global Initiative for Chronic Obstructive Pulmonary Disease (GOLD) criteria (18) and who had been using pMDI, pMDI with spacer of inhaler devices for at least three months prior to the study were enrolled to the study. The exclusion criteria included patients using other kinds of inhaler devices, a history of dementia, those who did not understand the Thai language, and a history of acute exacerbation (AE) of COPD or hospitalization due to AECOPD within the previous 6 weeks because the subjects with recent AECOPD had were already trained by pharmacists. One hundred and four COPD subjects met the inclusion criteria and written informed consent was obtained from all participants. The study was conducted in accordance with the Declaration of Helsinki (as revised in 2013). The study protocol was approved by the ethics committee of faculty of medicine, Chiang Mai university, Chiang Mai, Thailand (study code: MED-2562-06184, date of approval: $14^{\text {th }}$ May 2019) and filed under Clinical Trials Registry (study ID: TCTR20210702004, date of approval: 2 July 2021).

\section{Study procedure}

All enrolled COPD patients were assessed for their inhalation technique and inspiratory flow during their follow-up visit without prior notification by qualified respiratory nurses. The use of each inhaler device was evaluated by asking patients to demonstrate their inhalation techniques and inhalation flow using their prescribed devices containing placebo medications. They were asked to perform each step, so that all the steps could be clearly observed. A checklist was used to measuring the essential steps required for adequate drug delivery for each device, based on manufacturer provided instructions, and from previous studies (5), the seven steps of pMDI and the eight steps of pMDI with spacer (demonstrated in Table S1). When one or more errors were made regarding these essential steps, it was considered unlikely that a significant amount of medicine would be inhaled. In these cases, the inhalation technique was defined as incorrect. The inspiratory flow was also measured in all subjects using the In-Check DIAL inhaler training device (Clement Clerke 


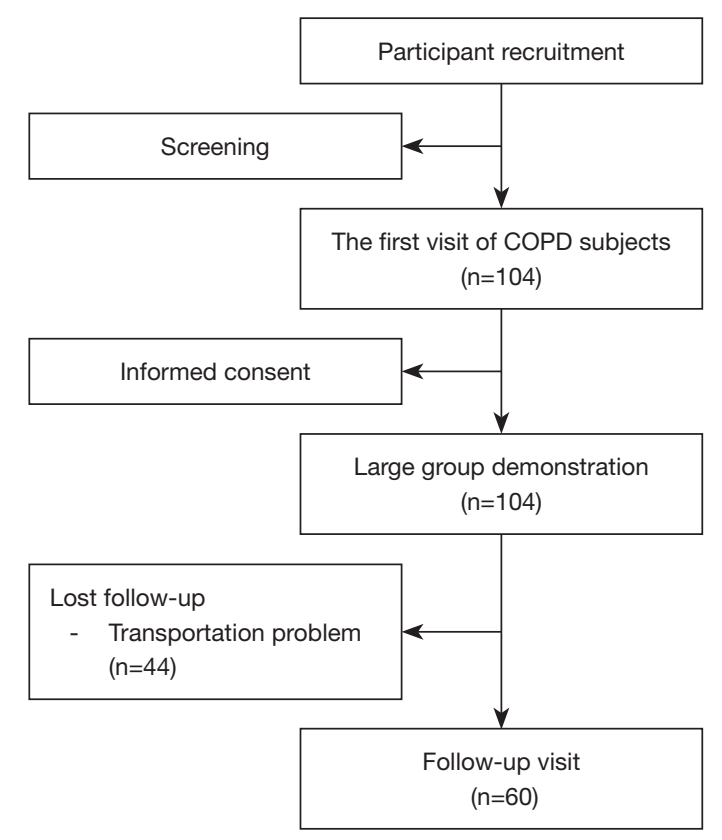

Figure 1 Study flow diagram. COPD, chronic obstructive pulmonary disease.

International Ltd., Harlow, UK). A flow rate of 30-60 L/min was defined as the appropriated inhalation flow for the measurement algorithm for pMDI, according to previous systematic review $(19,20)$. The respiratory nurses observed each step of the inhalation technique and recorded each incorrect step. After the assessment, all patients were given verbal instructions by large group demonstrations regarding the correct use of the inhalation devices (44 cases for $\mathrm{pMDI}$ and 60 cases for $\mathrm{pMDI}$ with spacer devices). The large group inhaler demonstration was conducted by one respiratory nurse. During the demonstration training, three respiratory nurses observed all patients and responded to the query from patients. This inhaler education session was conducted in the hospital hall a hall in the hospital. An average session lasted 15-20 minute for each session. One month later (post-training visits), all patients were requested to demonstrate their inhalation techniques and inspiratory flow again, and they were re-evaluated by the same groups of respiratory nurses.

All subjects underwent spirometry in accordance with guidelines of the American Thoracic Society (ATS) and the European Respiratory Society (ERS) (21) for measuring forced expiratory volume in the first second $\left(\mathrm{FEV}_{1}\right)$, forced vital capacity (FVC), and ratio of $\mathrm{FEV}_{1}$ to $\mathrm{FVC}\left(\mathrm{FEV}_{1} /\right.$ FVC), unless their medical records contained documented results of spirometry within the previous three months. The northern Thai dialect version of the COPD assessment test (CAT) (22) and a modified Medical Research Council (mMRC) (23) dyspnea score were administered to all subjects during their enrollment visit. The types of inhaler devices were also recorded. The other demographic data were also collected including age, sex, GOLD classification, comorbidities, history of AECOPD, and pharmacological therapy.

\section{Study size calculation}

The sample size of this study was calculated based on those from previous study (5). Based on the percentage of patients exhibiting an incorrect technique for pMDI ( $72.4 \%$ vs. $48.3 \%$ for pre and post training, respectively), and the sample size using the STATA version 15 (StataCorp, College Station, TX, USA), the one-sided was set and the $\mathrm{P}$ value and the power was set at 0.05 and 0.80 , respectively. On this basis, it was determined that at least 58 elderly with COPD subjects would be required for statistically significant comparison percentages between the pre-group training and post-group training in this study.

\section{Statistical analysis}

Data are presented as mean \pm standard deviation (SD) unless stated otherwise. Handling errors per device were defined as the percentage of subjects who incorrectly performed each step. Patients performing incorrect flow were defined as a percentage of subjects. Comparison percentages of the correct inhalation technique and inspiratory flow between pre-group training and post-group training visits within groups were analyzed using $\mathrm{McNemar}$ test. The subjects lost to follow-up were excluded from the pre- and postgroup training analysis. Statistical significance was accepted at $\mathrm{P}<0.05$. All statistical analyses were performed using STATA version 15 (StataCorp, College Station, TX, USA).

\section{Results}

A total of 104 elderly with COPD patients were included in this study. Forty-four subjects lost to follow-up due to transportation problem. The study flow is shown in the Figure 1. Subject demographics and clinical characteristics data are shown in Table 1. Subjects had a mean age of $70.9 \pm 8.3$ years old, $51(49.0 \%)$ were male, and the mean $\%$ predicted of $\mathrm{FEV}_{1}$ was $67.3 \pm 23.6$. Approximately $60 \%$ 
Table 1 Demographic and clinical characteristics of COPD patients

\begin{tabular}{|c|c|}
\hline Characteristics & $\mathrm{N}=104$ \\
\hline Age (years) & $70.9 \pm 8.3$ \\
\hline Male sex, n (\%) & $51(49.0)$ \\
\hline Body mass index $\left(\mathrm{kg} / \mathrm{m}^{2}\right)$ & $19.3 \pm 4.1$ \\
\hline$\%$ predicted $\mathrm{FEV}_{1}$ & $67.3 \pm 23.6$ \\
\hline Ratio of $\mathrm{FEV}_{1} / \mathrm{FVC}(\%)$ & $55.2 \pm 9.4$ \\
\hline \multicolumn{2}{|l|}{ GOLD classification } \\
\hline$A$ & $59(56.7)$ \\
\hline B & $24(23.1)$ \\
\hline $\mathrm{C}$ & $13(12.5)$ \\
\hline $\mathrm{D}$ & $8(7.7)$ \\
\hline mMRC score, median [IQR] & $1[1-2]$ \\
\hline CAT score median $[\mathrm{IQR}]$ & $4[2-8]$ \\
\hline Frequent $\mathrm{AE}$ in the previous year ( $\geq 2$ times/year) & $21(20.2)$ \\
\hline No. of $A E$ in the previous year, median [IQR] & $1[0-1]$ \\
\hline \multicolumn{2}{|l|}{ Co-morbidity } \\
\hline Cardiovascular disease & $44(42.3)$ \\
\hline Metabolic disease & $2(1.9)$ \\
\hline Cardiovascular + metabolic disease & $16(15.4)$ \\
\hline None & $42(40.4)$ \\
\hline \multicolumn{2}{|l|}{ Controller inhale medication } \\
\hline SABA & $36(34.6)$ \\
\hline ICS & $10(9.6)$ \\
\hline ICS + LABA & $58(55.8)$ \\
\hline \multicolumn{2}{|l|}{ Controller device } \\
\hline pMDI & $44(42.3)$ \\
\hline pMDI with spacer & $60(57.7)$ \\
\hline
\end{tabular}

Data are mean \pm SD or $n(\%)$, otherwise stated. COPD, chronic obstructive pulmonary disease; $\mathrm{FEV}_{1}$, forced expiratory volume in the first second; FVC, forced vital capacity; mMRC, modified Medical Research Council score; CAT, COPD assessment test; GOLD, Global Initiative for Chronic Obstructive Pulmonary Disease; $\mathrm{AE}$, acute exacerbation; SABA, short acting beta-2 agonist; ICS, inhale corticosteroid; LABA, long-acting beta-2 agonist; pMDI, pressurized metered-dose inhaler; IQR, interquartile range.

were classified in GOLD group A. Forty-four (42.3\%) and $60(57.7 \%)$ cases were prescribed the pharmacological therapy device with pMDI and pMDI with spacer, respectively. More data are shown in Table 1.
Thirty-three $(75.0 \%)$ and $49(81.7 \%)$ COPD patients performed at least one essential step incorrectly for pMDI and $\mathrm{pMDI}$ with spacer, respectively. For the analysis per device, percentages of incorrect essential steps, incorrect flow, and the overall (incorrect technique and flow) are presented in Table 2. The most frequent error displayed in the use of both devices was that patients breathed out too gently to residual volume $(50.0 \%$ and $53.3 \%$ for pMDI and $\mathrm{pMDI}$ with spacer, respectively). Patients performing incorrect flow (less than $<30 \mathrm{~L} / \mathrm{min}$ or greater than $60 \mathrm{~L} / \mathrm{min}$ ) were observed in both devices [28 cases $(63.6 \%)$ for $\mathrm{pMDI}$ and 33 cases $(55.0 \%)$ for pMDI with spacer]. For the overall evaluation (incorrect technique and flow), there were high percentage of subjects that performed incorrect technique and flow with $95.5 \%$ for pMDI and $90.0 \%$ for pMDI with spacer. More details are shown in Table 2.

At 1-month re-visit (post-training), a total of $57.7 \%$ (60/104) of COPD patients were re-assessed. Forty-four subjects lost to follow-up due to transportation problem. Comparisons of correct techniques and inspiratory flow before and after large group training visits are shown in Table 3. The large group demonstration training resulted in a statistically significant increase in the percentage of correct techniques in all devices $(26.7 \%$ vs. $56.7 \%, \mathrm{P}=0.001$ for correct technique, $41.7 \%$ vs. $62.7 \%, \mathrm{P}=0.026$ for correct flow, and $11.7 \%$ vs. $36.7 \%$, $\mathrm{P}$ value 0.001 for correct technique and flow). For pMDI, there were a statistically significant increase in the percentage of correct flow $(29.6 \%$ vs. $59.3 \%, \mathrm{P}=0.035)$ and both in correct of technique and flow $(7.4 \%$ vs. $37.0 \%, \mathrm{P}=0.008)$. For $\mathrm{pMDI}$ with spacer, only the percentage of correct technique was significantly improved $(21.2 \%$ vs. $54.5 \%, \mathrm{P}=0.007)$. More results are demonstrated in Table 3.

\section{Discussion}

This study has demonstrated that large group demonstration training method could improve the effectiveness of inhalation technique and inhalation flow in elderly with COPD patients. However, the study has also revealed that there are a high percentage of inhaler devices, including pMDI and pMDI with spacer, being incorrectly used routinely in elderly patients being treated for COPD.

A high percentage of errors were made when using in both pMDI (75.0\%) and pMDI with spacer (81.7\%). The results of this study are comparable to previous findings that have suggested the errors in using pMDI and pMDI with spacer were high with ranged from $63.5 \%$ to $95.7 \%$ 
Table 2 Percentages of mistakes per step, total percentages of patients making incorrect inhalation techniques per controller device

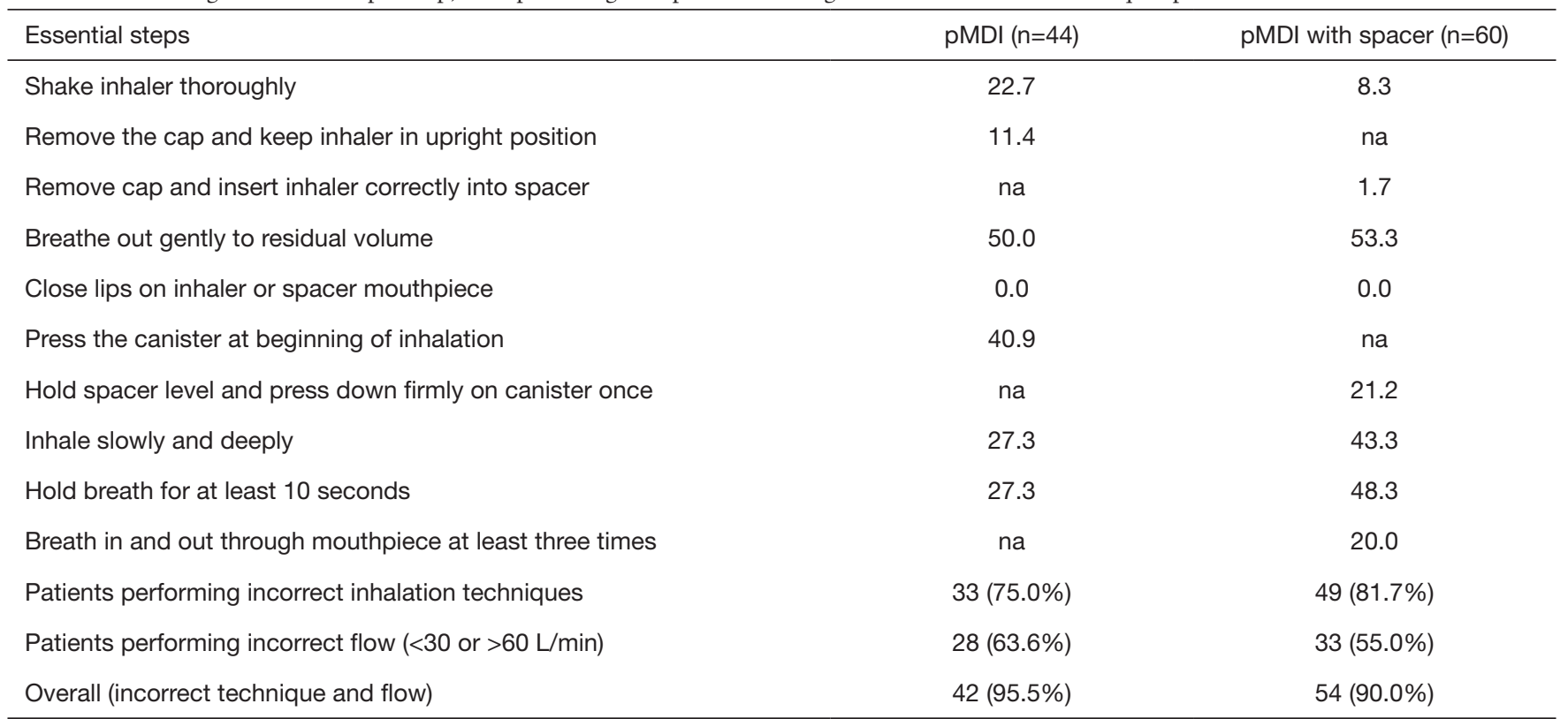

pMDI, pressurized metered-dose inhaler; na, not applicable to the device.

Table 3 Comparison of correct techniques and flow between routine visit and one month after a group training of controller devices in 60 COPD patients

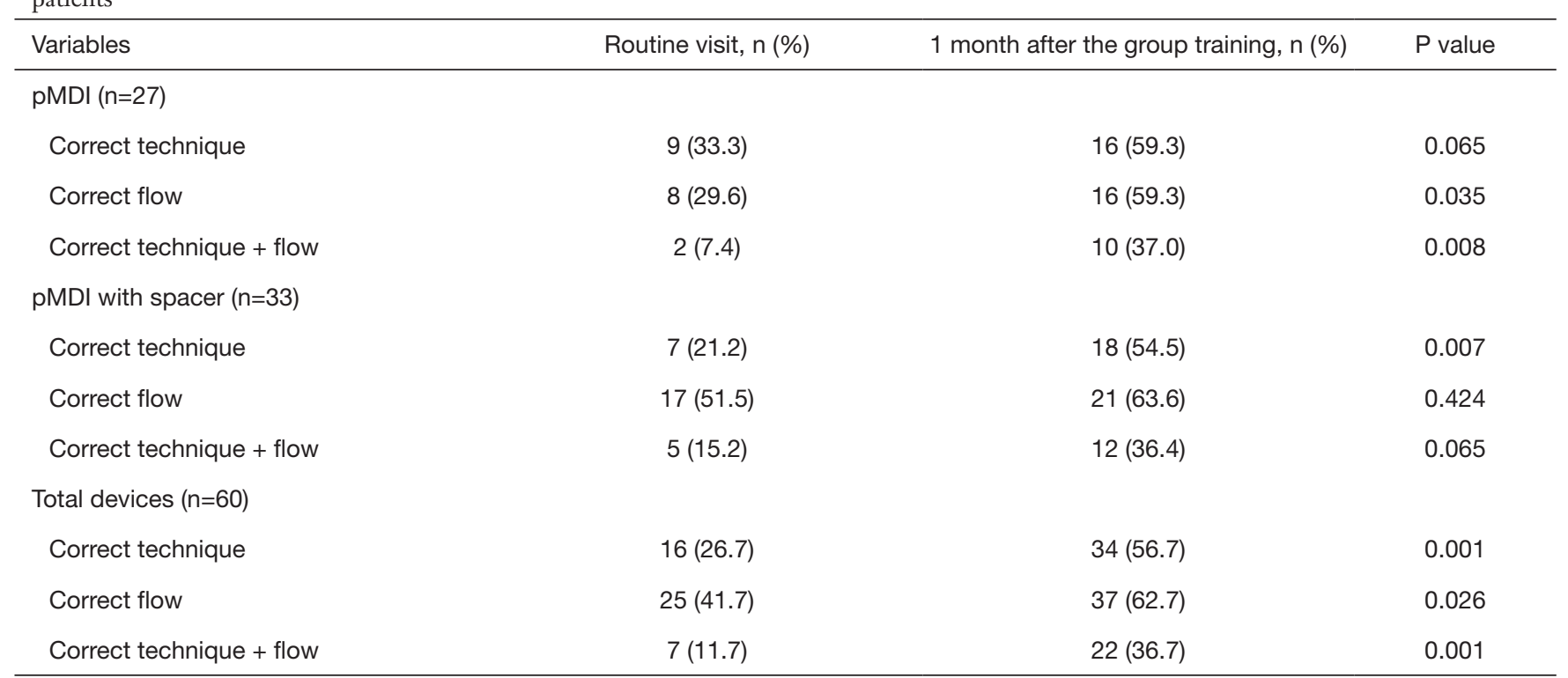

COPD, chronic obstructive pulmonary disease; pMDI, pressurized metered-dose inhaler.

(5-9) and $69.7 \%$ to $79.2 \%(5,7,8)$, respectively. This may be because the $\mathrm{pMDI}$ is inherently more difficult to use and needs proper coordination. This study has shown that the error in the "press the canister at beginning of inhalation" step was $40.9 \%$ in pMDI. Adding a spacer to the pMDI appears to help eliminate poor hand-lung coordination (24). The results of this study confirm this finding because in the pMDI with spacer groups, the errors in the "hold spacer level and press down firmly on canister once" step was significantly lower (21.2\%). 
This study has also demonstrated that the "breathe out gently to residual volume" step was the most frequently performed incorrectly in both devices $(50.0 \%$ and $53.3 \%$ for $\mathrm{pMDI}$ and $\mathrm{pMDI}$ with spacer, respectively). These results mirror previous studies that show this was the common error in COPD subjects, with a range from $40.0 \%$ to $54.5 \%(5,7,9)$. This finding was shown in both the inhalation technique and the inspiratory flow. This study showed that the inappropriate flow when using in pMDI and pMDI with spacer was common $(63.6 \%$ and $55.0 \%$, respectively). However, Al-Showair et al. showed a higher percentage $(93.5 \%)$ of COPD subjects use the greater flow than $60 \mathrm{~L} / \mathrm{min}$ with the pMDI (10).

This study confirms a significant improvement in inhalation technique after a large group demonstration and training (44 cases/group and 60 cases/group for pMDI or pMDI with spacer devices, respectively), and is the first study on a large group demonstration (greater than 40 cases/group) in inhalation training. The results show an improvement in both inhalation technique and inhalation flow in COPD patients. These results are comparable to previous studies that focused on the face-to-face training and small group training on inhalation techniques $(5,14,25)$. Based on the results of this study, the large group demonstration training on pMDI inhaler-use in COPD patients should be applied and promoted regularly within the context of a time-limited and busy COPD clinic $(5,25-27)$.

\section{Strength and limitation of this study}

This study has strengths that should be considered. Firstly, this is the first study on a large group demonstration training method (greater than 40 cases/group) in inhalation training for pMDI that are frequently prescribed in community hospitals in Thailand. Secondly, the study represents a real-world clinical practice. Thus, elderly with COPD patients were assessed in their inhaler use without prior notification. Thirdly, the inspiratory flow was assessed using the in-check device for confirming the "inhale slowly and deeply" step instead of the used of observation method only. However, this study had limitations. Firstly, this study was conducted in a single community hospital and therefore cannot exclude selection bias. This may limit the application of the results in other settings. As the center is a community hospital, the errors in inhalation techniques and inspiratory flow were common. It might be postulated that the inhalation technique of elderly with COPD patients in general practice clinics may be different. Secondly, a control group was not included in this study. Therefore, age- and sex-matched controls should be included to determine whether the percentage of correct inhalation technique differs in comparison with control group.

\section{Conclusions}

In real-world practice, instances of incorrect inhalation techniques and inappropriate inspiratory flow of pMDI and pMDI with spacer devices in COPD patients were very common. Large group demonstration training method was proved significantly increases the effectiveness of inhalation techniques and appropriate inspiratory flow for pMDI and pMDI with spacer in elderly with COPD.

\section{Acknowledgments}

The authors would like to thank all subjects who kindly participated in this study. The authors acknowledge the physicians and nurses of the Division of Pulmonary, Critical Care and Allergy, Department of Internal Medicine, Faculty of Medicine, Chiang Mai University and Chiang Dao hospital for their contribution to this study. The authors would like to thank Mrs. Joan Elizabeth Peagam, Research administration section, Faculty of Medicine, Chiang Mai University for native English proofreading.

Funding: None.

\section{Footnote}

Reporting Checklist: The authors have completed the STROBE reporting checklist. Available at https://jtd. amegroups.com/article/view/10.21037/jtd-21-1612/rc

Data Sharing Statement: Available at https://jtd.amegroups. com/article/view/10.21037/jtd-21-1612/dss

Conflicts of Interest: All authors have completed the ICMJE uniform disclosure form (available at https://jtd.amegroups. com/article/view/10.21037/jtd-21-1612/coif). The authors have no conflicts of interest to declare.

Ethical Statement: The authors are accountable for all aspects of the work in ensuring that questions related to the accuracy or integrity of any part of the work are appropriately investigated and resolved. The study was conducted in accordance with the Declaration of Helsinki (as revised in 2013). The study protocol was 
approved by the ethics committee of faculty of medicine, Chiang Mai university, Chiang Mai, Thailand (study code: MED-2562-06184, date of approval: 14th May 2019) and filed under Clinical Trials Registry (study ID: TCTR20210702004, date of approval: 2 July 2021). Written informed consent was obtained from all participants.

Open Access Statement: This is an Open Access article distributed in accordance with the Creative Commons Attribution-NonCommercial-NoDerivs 4.0 International License (CC BY-NC-ND 4.0), which permits the noncommercial replication and distribution of the article with the strict proviso that no changes or edits are made and the original work is properly cited (including links to both the formal publication through the relevant DOI and the license). See: https://creativecommons.org/licenses/by-nc-nd/4.0/.

\section{References}

1. Wright J, Brocklebank D, Ram F. Inhaler devices for the treatment of asthma and chronic obstructive airways disease (COPD). Qual Saf Health Care 2002;11:376-82.

2. Purohit AN, Patel PP, Gandhi AM, et al. An evaluation of impact of educational interventions on the technique of use of metered-dose inhaler by patients. Indian J Pharmacol 2017;49:194-200.

3. Lavorini F, Usmani OS. Correct inhalation technique is critical in achieving good asthma control. Prim Care Respir J 2013;22:385-6.

4. Price D, Roche N, Christian Virchow J, et al. Device type and real-world effectiveness of asthma combination therapy: an observational study. Respir Med 2011;105:1457-66.

5. Pothirat C, Chaiwong W, Phetsuk N, et al. Evaluating inhaler use technique in COPD patients. Int J Chron Obstruct Pulmon Dis 2015;10:1291-8.

6. Souza ML, Meneghini AC, Ferraz E, et al. Knowledge of and technique for using inhalation devices among asthma patients and COPD patients. J Bras Pneumol 2009;35:824-31.

7. Arora P, Kumar L, Vohra V, et al. Evaluating the technique of using inhalation device in COPD and bronchial asthma patients. Respir Med 2014;108:992-8.

8. Ganguly A, Das AK, Roy A, et al. Study of Proper use of Inhalational Devices by Bronchial Asthma or COPD Patients Attending a Tertiary Care Hospital. J Clin Diagn Res 2014;8:HC04-7.

9. Vytrisalova M, Hendrychova T, Touskova T, et al.
Breathing Out Completely Before Inhalation: The Most Problematic Step in Application Technique in Patients With Non-Mild Chronic Obstructive Pulmonary Disease. Front Pharmacol 2019;10:241.

10. Al-Showair RA, Tarsin WY, Assi KH, et al. Can all patients with COPD use the correct inhalation flow with all inhalers and does training help? Respir Med 2007;101:2395-401.

11. Sulaiman I, Cushen B, Greene G, et al. Objective Assessment of Adherence to Inhalers by Patients with Chronic Obstructive Pulmonary Disease. Am J Respir Crit Care Med 2017;195:1333-43.

12. Amini S, Ghasemi A, Solduzian M, et al. Is Inhaler Technique Associated with Quality of Life in Patients with Chronic Obstructive Pulmonary Disease? Curr Ther Res Clin Exp 2020;93:100608.

13. Padmanabhan $M$, Tamilarasu K, Rajaram $M$, et al. Inadequate inhaler technique, an everlasting problem, is associated with poor disease control - A cross sectional study. Adv Respir Med 2019;87:217-25.

14. Usmani OS, Lavorini F, Marshall J, et al. Critical inhaler errors in asthma and COPD: a systematic review of impact on health outcomes. Respir Res 2018;19:10.

15. Capstick TG, Clifton IJ. Inhaler technique and training in people with chronic obstructive pulmonary disease and asthma. Expert Rev Respir Med 2012;6:91-101; quiz 102-3.

16. King TL, Kho EK, Tiong YH, et al. Comparison of effectiveness and time-efficiency between multimedia and conventional counselling on metered-dose inhaler technique education. Singapore Med J 2015;56:103-8.

17. van der Palen J, Klein JJ, Kerkhoff AH, et al. Evaluation of the long-term effectiveness of three instruction modes for inhaling medicines. Patient Educ Couns 1997;32:S87-95.

18. Rabe KF, Hurd S, Anzueto A, et al. Global strategy for the diagnosis, management, and prevention of chronic obstructive pulmonary disease: GOLD executive summary. Am J Respir Crit Care Med 2007;176:532-55.

19. Haidl P, Heindl S, Siemon K, et al. Inhalation device requirements for patients' inhalation maneuvers. Respir Med 2016;118:65-75.

20. Mahler DA. The role of inspiratory flow in selection and use of inhaled therapy for patients with chronic obstructive pulmonary disease. Respir Med 2020;161:105857.

21. Miller MR, Hankinson J, Brusasco V, et al. Standardisation of spirometry. Eur Respir J 2005;26:319-38.

22. Pothirat $\mathrm{C}$, Chaiwong $W$, Phetsuk $\mathrm{N}$, et al. Dialectal influence on chronic pulmonary disease assessment test: the reliability and validity study. Int J Chron Obstruct 
Pulmon Dis 2015;10:541-8.

23. Bestall JC, Paul EA, Garrod R, et al. Usefulness of the Medical Research Council (MRC) dyspnoea scale as a measure of disability in patients with chronic obstructive pulmonary disease. Thorax 1999;54:581-6.

24. Anderson G, Johnson N, Mulgirigama A, et al. Use of spacers for patients treated with pressurized metered dose inhalers: focus on the VENTOLIN ${ }^{\mathrm{TM}}$ Mini Spacer. Expert Opin Drug Deliv 2018;15:419-30.

25. Nguyen TS, Nguyen TLH, Van Pham TT, et al.

Cite this article as: Choomuang W, Pothirat C, Chaiwong W, Liwsrisakun C, Theerakittikul T, Phetsuk N, Chanayat P. The effectiveness of large group demonstration training method on the use of pressurized metered-dose inhaler in elderly with chronic obstructive pulmonary disease. J Thorac Dis 2022;14(4):919-926. doi: 10.21037/jtd-21-1612
Pharmacists' training to improve inhaler technique of patients with COPD in Vietnam. Int J Chron Obstruct Pulmon Dis 2018;13:1863-72.

26. Steier J, Trammer T, Cloes RM, et al. Optical feedback training of inhalation with Autohaler and Turbuhaler in COPD patients. Lung 2003;181:183-92.

27. Crompton GK, Barnes PJ, Broeders M, et al. The need to improve inhalation technique in Europe: a report from the Aerosol Drug Management Improvement Team. Respir Med 2006;100:1479-94. 
Supplementary

Table S1 The essential steps checklist for inhaler devices

\begin{tabular}{|c|c|c|}
\hline Essential steps & pMDI & pMDI with spacer \\
\hline Shake inhaler thoroughly & 1. $\square$ & 1. $\square$ \\
\hline Remove the cap and keep inhaler in upright position & 2. $\square$ & na \\
\hline Remove cap and insert inhaler correctly into spacer & na & 2. $\square$ \\
\hline Breathe out gently to residual volume & 3. $\square$ & 3. $\square$ \\
\hline Close lips on inhaler or spacer mouthpiece & 4. $\square$ & 4. $\square$ \\
\hline Press the canister at beginning of inhalation & 5. $\square$ & na \\
\hline Hold spacer level and press down firmly on canister once & na & 5. $\square$ \\
\hline Inhale slowly and deeply & 6. $\square$ & 6. $\square$ \\
\hline Hold breath for at least 10 seconds & 7. $\square$ & 7. $\square$ \\
\hline Breath in and out through mouthpiece at least three times & na & 8. $\square$ \\
\hline Patients performing incorrect inhalation techniques & $\square$ & $\square$ \\
\hline Patients performing incorrect flow ( $<30$ or $>60 \mathrm{~L} / \mathrm{min})$ & $\square$ & $\square$ \\
\hline Overall (incorrect technique and flow) & $\square$ & $\square$ \\
\hline
\end{tabular}

pMDI, pressurized meter dose inhaler; na, not applicable to the device. 